\title{
FADS1 rs174550 genotype and high linoleic acid diet modify plasma PUFA phospholipids in a dietary intervention study
}

\author{
Topi Meuronen $^{1}$ (D) Maria A. Lankinen ${ }^{1}$. Olli Kärkkäinen ${ }^{2} \cdot$ Markku Laakso $^{3}$. Jussi Pihlajamäki ${ }^{1,4}$. \\ Kati Hanhineva ${ }^{1,5,6} \cdot$ Ursula Schwab ${ }^{1,4}$
}

Received: 17 June 2021 / Accepted: 18 October 2021 / Published online: 31 October 2021

(c) The Author(s) 2021

\begin{abstract}
Introduction Fatty acid desaturase 1 (FADS1) gene encodes for delta-5 desaturase enzyme which is needed in conversion of linoleic acid (LA) to arachidonic acid (AA). Recent studies have shown that response to dietary PUFAs differs between the genotypes in circulating fatty acids. However, interactions between the FADSI genotype and dietary LA on overall metabolism have not been studied.

Objectives We aimed to examine the interactions of FADS1 rs174550 genotypes (TT and CC) and high-LA diet to identify plasma metabolites that respond differentially to dietary LA according to the FADS1 genotype.

Methods A total of 59 men (TT $n=26$, CC $n=33$ ) consumed a sunflower oil supplemented diet for 4 weeks. Daily dose of 30,40 , or $50 \mathrm{ml}$ was calculated based on body mass index. It resulted in 17-28 $\mathrm{g}$ of LA on top of the usual daily intake. Fasting plasma samples at the beginning and at the end of the intervention were analyzed with LC-MS/MS non-targeted metabolomics method.

Results At the baseline, the carriers of FADS1 rs174550-TT genotype had higher abundance of long-chain PUFA phospholipids compared to the FADS1 rs174550-CC one. In response to the high-LA diet, LA phospholipids and long-chain acylcarnitines increased and lysophospholipids decreased in fasting plasma similarly in both genotypes. LysoPE (20:4), LysoPC (20:4), and PC (16:0_20:4) decreased and cortisol increased in the carriers of rs 174550-CC genotype; however, these genotype-diet interactions were not significant after correction for multiple testing.

Conclusion Our findings show that both FADS1 rs 174550 genotype and high-LA diet modify plasma phospholipid composition.
\end{abstract}

Trial registration The study was registered to ClinicalTrials: NCT02543216, September 7, 2015 (retrospectively registered).

Keywords FADS1 $\cdot$ Linoleic acid $\cdot$ Metabolomics $\cdot$ Personalized nutrition $\cdot$ Diet $\cdot$ Human

Topi Meuronen

topi.meuronen@uef.fi

1 Institute of Public Health and Clinical Nutrition, University of Eastern Finland, PO box 1627, 70211 Kuopio, Finland

2 School of Pharmacy, Faculty of Health Sciences, University of Eastern Finland, Kuopio, Finland

3 Institute of Clinical Medicine, Internal Medicine, University of Eastern Finland and Kuopio University Hospital, Kuopio, Finland

4 Department of Medicine, Endocrinology and Clinical Nutrition, Kuopio University Hospital, Kuopio, Finland

5 Department of Life Technologies, Food Chemistry and Food Development Unit, University of Turku, Turku, Finland

6 Department of Biology and Biological Engineering, Division of Food and Nutrition Science, Chalmers University of Technology, Gothenburg, Sweden

$\begin{array}{ll}\text { Abbreviations } \\ \text { AA } & \text { Arachidonic acid } \\ \text { AUC } & \text { Area under the curve } \\ \text { D5D } & \text { Delta-5-desaturase } \\ \text { D6D } & \text { Delta-6-desaturase } \\ \text { DGLA } & \text { Dihomo-gamma-linolenic acid } \\ \text { ESI } & \text { Electrospray ionization } \\ \text { ETA } & \text { Eicosatetraenoic acid } \\ \text { FADS } & \text { Fatty acid desaturase } \\ \text { GLA } & \text { Gamma-linolenic acid } \\ \text { HDL } & \text { High-density lipoprotein } \\ \text { hs-CRP } & \text { High-sensitivity C-reactive protein } \\ \text { LA } & \text { Linoleic acid } \\ \text { LCAC } & \text { Long-chain acylcarnitine } \\ \text { LC-MS } & \text { Liquid chromatography-mass spectrometry } \\ \text { LysoPC } & \text { Lysophosphatidylcholine }\end{array}$




$\begin{array}{ll}\text { LysoPE } & \text { Lysophosphatidylethanolamine } \\ \text { MUFA } & \text { Monounsaturated fatty acid } \\ \text { PC } & \text { Phosphatidylcholine } \\ \text { PLS-DA } & \text { Partial least-squares discriminant analysis } \\ \text { PUFA } & \text { Polyunsaturated fatty acid } \\ \text { QC } & \text { Quality control } \\ \text { SA } & \text { Stearidonic acid } \\ \text { VIP } & \text { Variable importance in projection }\end{array}$

\section{Introduction}

Composition of human metabolome is dependent on the genes encoding enzymes for metabolic pathways, and availability of specific substrates. Some of metabolites, precursors, or intermediates of the metabolism are derived directly from diet. These metabolites are metabolized to produce wide range of molecules which act as cellular signaling factors and structural components. Thus, the human metabolome is dependent on both diet and variants in the genes encoding enzymes for metabolism. In the current study, we aimed to investigate how genetic variation in a polyunsaturated fatty acid (PUFA) metabolism-related fatty acid desaturase 1 gene $(F A D S 1)$ affects subjects' metabolic profiles and responses to a high linoleic acid (LA, 18:2n6) diet.

Decreased incidence of type 2 diabetes and cardiovascular diseases are associated with higher levels of n-6 LA and long-chain n-3 PUFAs in circulation but not with long-chain n-6 arachidonic acid (AA, 20:4n6) [1-3]. However, levels of PUFAs in circulation are not solely determined by their dietary intakes. Dietary fatty acids and variation in the genes involved in fatty acid metabolism explain some of the variation in fatty acid composition of plasma lipids [4]. Dietary sources for essential fatty acids, LA and alpha-linolenic acid (ALA, 18:3n3), include plants and plant-derived oils [5]. FADS1 encodes for fatty acid delta-5 desaturase (D5D) enzyme. Enzymatic route involving D5D is responsible for the conversion of LA and ALA to AA and eicosapentaenoic acid (EPA, 20:5n3), respectively. First, fatty acid delta-6 desaturase (D6D) converts LA and ALA, both from dietary sources, to gamma-linolenic acid (GLA, 18:3n6) and stearidonic acid (SA, 18:4n3), respectively. Fatty acid elongase 5 enzyme elongates GLA and SA to dihomo-gamma-linolenic acid (DGLA, 20:3n6) and eicosatetraenoic acid (ETA, 20:4n3), which are further desaturated by D5D to AA and EPA [6]. Estimated enzyme activity of D5D is modified by genetic variants in $F A D S 1$, and the conversion rate of LA to AA differs between the carriers of different genotypes [7, 8].

Allelic frequencies of $F A D S$ variants differ across populations [9]. FADS haplotype, which is associated with lower plasma proportions of AA and DHA, occurs at a frequency of $1 \%$ in African population, $97 \%$ in native Americans, and 25-50\% in Europeans and Asians. This FADS1 haplotype associates with $43 \%$ and $24 \%$ lower plasma levels of AA and DHA, respectively, compared to the homozygous haplotype with more efficient conversion [10]. In addition to human genetic ability to metabolize dietary PUFAs, the intake of PUFAs varies from country to country. The consumption of $\mathrm{n}-6$ LA has been increasing during the last 100 years in the US, and currently, $\mathrm{n}-6 / \mathrm{n}-3$ ratio ranges from $\sim 10: 1$ in the US (1999) [11] to 3:1 in Finland (The National FINDIET 2017 Survey). The gene expression of $F A D S 1$ is affected by several intronic variants in the FADS gene cluster [12-15]. Carriers of alleles associated with higher $F A D S 1$ expression have higher estimated activity of D5D $[7,8,16]$ and thus higher rates of conversion of LA to AA, which causes differences in the fatty acid composition of plasma lipids. Cross-sectional studies indicate that genetic variants of $F A D S I$ have an impact on several cardiometabolic risk factors. Lower plasma concentrations of triglycerides and higher high-density lipoprotein (HDL) particles [15], especially large and very large HDL particles [17], and glucose [18], are related to the variant with higher D5D activity. These subjects are at higher risk for developing type 2 diabetes [18]. Considering the differences in the dietary intake of PUFAs across the populations and the impact of FADS1 variants on fatty acid metabolism and metabolic traits, the interactions of this gene and diet should be studied to further reveal its effects on human health.

We have recently shown that the impact of dietary LA on high-sensitivity $\mathrm{C}$-reactive protein (hs-CRP) concentration depends on the rs174550 variant of FADS1 [16]. Mechanisms how dietary LA and genetic variants of FADS1 are associated with the inflammatory responses are poorly understood. We applied non-targeted LC-MS metabolomics in a study, in which subjects with different FADS1 rs174550 genotypes received a diet rich in LA for 4 weeks. We aimed to find metabolites that could explain differences seen on hs-CRP. Furthermore, we investigated the interactions between FADSI rs174550 genotypes and a diet rich in LA. The difference in metabolic profiles at the baseline and the rate of conversion of LA to AA potentially modulates the response to dietary PUFAs. Utilization of non-targeted metabolomics approach for fasting plasma samples allowed us to estimate the differences between endogenous metabolism of fatty acids and overall metabolome between FADS1 rs174550-TT and -CC genotypes and the effects of the high-LA diet.

\section{Materials, subjects, and methods}

\section{FADSDIET1 intervention}

The full description of the FADSDIET1 intervention has been previously reported [16]. In brief, carriers of the FADS1 rs 174550 TT and CC genotypes were invited from the Metabolic Syndrome In Men (METSIM) cohort. 
Table 1 Clinical characteristics of participants at baseline according to FADS1 rs 174550 genotype

\begin{tabular}{lccc}
\hline & $\begin{array}{l}\text { TT }(n=26) \\
\text { Median }(\mathrm{IQR})\end{array}$ & $\begin{array}{l}\text { CC }(n=33) \\
\text { Median }(\mathrm{IQR})\end{array}$ & $p^{1}$ \\
\hline Age, years & $55.0(53.0 ; 56.8)$ & $59.0(57.0 ; 61.0)$ & $8.30 \mathrm{E}-05$ \\
Body weight, $\mathrm{kg}$ & $81.4(73.5 ; 88.3)$ & $79.7(73.7 ; 83)$ & 0.536 \\
BMI, kg/m ${ }^{2}$ & $25.7(23.6 ; 27.6)$ & $24.9(22.5 ; 26.6)$ & 0.151 \\
Waist circumference, cm & $95.0(89.3 ; 100.0)$ & $95.4(90.0 ; 98.5)$ & 0.748 \\
Serum fasting total cholesterol, mmol/L & $5.3(4.8 ; 5.6)$ & $5.5(4.5 ; 6.3)$ & 0.292 \\
Serum fasting HDL cholesterol, mmol/L & $1.4(1.2 ; 1.6)$ & $1.4(1.1 ; 1.5)$ & 0.988 \\
Serum fasting LDL cholesterol, mmol/L & $3.4(2.8 ; 3.6)$ & $3.3(2.7 ; 4)$ & 0.861 \\
Serum fasting triglycerides, mmol/L & $1.0(0.8 ; 1.3)$ & $1.2(1.0 ; 1.6)$ & 0.055 \\
Plasma fasting glucose, mmol/L & $5.6(5.3 ; 5.9)$ & $5.7(5.5 ; 6)$ & 0.232 \\
Plasma fasting insulin, mU/L & $6.7(5.1 ; 10.0)$ & $7.9(5.4 ; 9.7)$ & 0.703 \\
Systolic blood pressure, $\mathrm{mmHg}$ & $129.0(118.8 ; 133.8)$ & $125.0(118.0 ; 134.0)$ & 0.652 \\
Diastolic blood pressure, $\mathrm{mmHg}$ & $82.5(77.5 ; 86.8)$ & $81.0(77.0 ; 89.0)$ & 0.994 \\
Use of statins, $n$ (\%) & $2(8)$ & $2(6)$ & \\
\hline
\end{tabular}

Data are presented as median and interquartile range (IQR)

$p^{1}$; Mann-Whitney's $U$ test for baseline differences between the FADS1 rs174550 TT and CC genotypes
Altogether, 59 healthy non-diabetic men with FADS1 rs174550 TT genotype $(n=26)$ and CC genotype $(n=33)$ completed the intervention (Online Resource 1). The carriers of the CC genotype were significantly older compared to the carriers of the TT genotype, but there were no other significant differences in the clinical markers (Table 1). Carriers of the FADS1 rs174550 TT genotype had significantly higher estimated D5D activity in plasma cholesteryl esters before the intervention [16]. Participants consumed their habitual diets throughout the intervention with the 30,40 , or $50 \mathrm{ml} /$ day sunflower oil supplementation. Sunflower oil dosing was dependent on BMI. The dosing of sunflower oil supplementation was estimated as a percentage of total energy intake to ensure similar relative supplementation to all subjects despite of their BMI. The supplementation provided approximately 17-28 g LA on top of normal daily intake. Fasting plasma samples were collected before and after the 4-week intervention. A 4-day food record was collected before the intervention and a 7-day food record during the intervention. Portion sizes were weighted or estimated using household measures and pictures of portion sizes. Food records were checked by a clinical nutritionist at return. Food records were analyzed by the AivoDiet nutrient calculation software (version 2.0.2.1; Aivo Finland). The study plan was approved by the Ethical Committee of the Hospital District of Northern Savo and all the treatments were carried out according to the Declaration of Helsinki. There were no available data on the differences in the response to dietary LA between the carriers of different FADS1 genotypes at the time of designing the study, so the power calculation was based on the effect of FADS1 rs174550 genotype on the plasma fatty acids. Based on the cross-sectional data in the
METSIM study, there is $95 \%$ power to observe significant differences $(30 \%)$ between the carriers of the TT and CC genotype, $\alpha=0.05$, in the proportion of plasma AA with ten participants/group [16]. It is likely that a larger, $>10$, sample size is needed to observe significant differences on the plasma metabolites with non-targeted metabolomics. Based on these assumptions, the sample size was estimated to $30 /$ group.

\section{Metabolomics analysis}

Non-targeted liquid chromatography-mass spectrometry-based metabolic profiling analysis was performed at Afekta Technologies Ltd. (www.afekta.com) using reversed-phase (RP) and hydrophilic interaction chromatographies (HILIC) in positive and negative electrospray ionization (ESI). An aliquot of the plasma sample, 100 $\mu \mathrm{L}$, was mixed with $400 \mu \mathrm{L}$ of acetonitrile and mixed by pipetting. Samples were centrifuged at $18,000 \times g$ for $10 \mathrm{~min}$ at $4{ }^{\circ} \mathrm{C}$ to filter through $0.2 \mu \mathrm{m}$ polytetrafluoroethylene filters in a 96 -well plate. Small aliquots $(2-5 \mu \mathrm{L})$ were taken from the plasma samples, mixed together in one tube, and used as the quality control sample (QC) in the analysis. The samples were analyzed by liquid chromatography-mass spectrometry (LC-MS), consisting of a 1290 Infinity Binary UPLC coupled with a 6540 UHD Accurate-Mass Q-TOF (Agilent Technologies). Zorbax Eclipse XDB-C18 column $(2.1 \times 100 \mathrm{~mm}, 1.8 \mu \mathrm{m}$; Agilent Technologies) was used for the RP separation and an Acquity UPLC BEH amide column (Waters) for the HILIC separation. After each chromatographic run, the ionization was carried out using jet stream ESI in the positive and negative mode. The collision energies for the MS/MS 
analysis were selected as 10,20 , and $40 \mathrm{~V}$, for compatibility with spectral databases.

Data were collected by "Find by Molecular Feature" algorithm in MassHunter Qualitative Analysis B.07.00 software (Agilent Technologies, USA). The allowed ion species in $\operatorname{ESI}(+):[\mathrm{M}+\mathrm{H}]+,[\mathrm{M}+\mathrm{Na}]+,[\mathrm{M}+\mathrm{K}]+$, $[\mathrm{M}+\mathrm{NH} 4]+$, and $[2 \mathrm{M}+\mathrm{H}]+$, and in $\operatorname{ESI}(-):[\mathrm{M}-\mathrm{H}]-$, $[\mathrm{M}+\mathrm{Cl}]-,[\mathrm{M}+\mathrm{HCOO}]-,[\mathrm{M}+\mathrm{CH} 3 \mathrm{COO}]-$, and $[2 \mathrm{M}-\mathrm{H}]-$. Signals with height $\geq 3000$ counts and $\geq 2$ ions were included in the compound list. Peak spacing tolerance for isotope grouping was $0.0025 \mathrm{~m} / \mathrm{z}$ plus $7 \mathrm{ppm}$, with isotope model for common organic molecules. We used Mass Profiler Professional (Agilent Technologies) for peak alignment. The data were combined in one.cef file after the first initial alignment, against which the original raw data were reanalyzed with compound mass tolerance was $\pm 15 \mathrm{ppm}$, retention time $\pm 0.150 \mathrm{~min}$, and symmetric expansion value for chromatograms $\pm 35.0 \mathrm{ppm}$. Peak alignment and data cleanup were performed with Mass Profiler Professional software.

\section{Data preprocessing}

The signal intensities of the molecular features were corrected for the drift pattern caused by the long LC-MS run. Regularized cubic spline regression was fit separately for each signal on the QC samples and the feature abundances of all samples were normalized using the acquired drift function [19]. Prior to data filtering, the data matrix was divided into four different matrixes, genotypes, and visits separately. These matrixes were filtered with $50 \%$ rule; if metabolite is present in over $50 \%$ of any taken group, it will be selected for further analyses. Filtering reduced the percentage of missing values from 38 to $20 \%$. Number of features decreased from 12,619 to 10,427. After filtering, the data were $\log 10$ transformed and missing values were imputed by random forest with ' missForest' $\mathrm{R}$ package [20]. Maximum number of iterations were set to 10. Features with mass over $1000 \mathrm{Da}$ and average intensity less than 50000 were removed. Number of features decreased from 10,427 to 3452 after filtering steps. These 3452 features were used in statistical analyses. Before multivariate statistical analyses, the data were normalized to quantiles and autoscaled.

\section{Statistical analyses}

Metabolite profiles at the baseline were compared with the unpaired Mann-Whitney's $U$ test and paired version was applied to compare differences between baseline and week 4 timepoints. To analyze differences on the responses to the high-LA diet between genotypes, later referred as genotype $\times$ diet interactions, metabolite measurements were rank normalized and analyzed using linear mixed effect model using R statistical software and nlme package (version 3.1). Metabolite measurement was used as a dependent variable, genotype $\mathrm{x}$ visit interaction, genotype, and visit were set as fixed effect, and subject identifier as a random effect. For metabolomic data, Benjamini-Hochberg FDR correction for multiple comparisons was used for $p$ values and applied for all 3452 features. FDR $p<0.05$ was considered as statistically significant and unadjusted $p$ values $<0.05$ as nominally significant. The nutrient intake data were analyzed with the same univariate methods than metabolomic data and $p<0.05$ was considered as statistically significant. Partial least-squares discriminant analyses (PLS-DA) were performed with the R package "mixOmics" [21]. Pre-intervention differences in metabolic profiles between the carriers of the FADS1 rs174550-TT and -CC genotypes were analyzed with PLS-DA. Changes within both genotypes were also analyzed with the multilevel PLS-DA, which is a paired extension of traditional PLS-DA and can be considered as a multivariate version of a traditional univariate $t$ test. The performance of PLS-DA models was assessed with receiver-operating characteristics curves and area under the curve (AUC). A number of components in final models were evaluated with the function "perf"; 2,3 and 2 components for baseline, the TT and CC genotype models. Classification error rates indicate robust models. AUC and $p$ values for PLS-DA models: baseline (comp1 0.9615 1.485e-09, comp2 $15.761 \mathrm{e}-11$ ), TT genotype (comp1 0.8595 8.7e-06, comp2 $0.98082 .716 \mathrm{e}-09$ and comp3 0.9956 8.738e-10), and CC genotype (comp1 0.88616 .941 e-08, comp2 0.9578 1.627e10). Sizes of changes within groups during the intervention were estimated by Cohen's $d$ with the corrections for small sample sizes [22]. R packages ComplexHeatmap v. 2.2.0 [23] and ggpubr v. 0.4.0 were used for data visualization.

\section{Identification of metabolites}

Features with average variable importance in projection value (VIP) $>1.5$ on the model for baseline differences and both multilevel models for genotypes were selected for identification. Features with unadjusted $p$ value $<0.05$ were selected for identification. Metabolites of interest were identified with three different levels. Level 1 identifications were matched against their mass, retention time, and MS/MS spectra ions from in-house library (commercial standards). Level 2 identification was matched against databases (MSDIAL library version 3.96 [24], HMDB [25], Metlin [26]) and in-house library including putatively identified compounds by their mass and MS/MS fragmented ions. Level III were predicted based on the fragmentation spectra, including in silico fragmentation. 
Table 2 Dietary intake of nutrients before (4-day food records) and during (7-day food records) the intervention in the carriers of the FADS1 rs174550 TT and CC genotypes

\begin{tabular}{|c|c|c|c|c|c|c|c|c|}
\hline & \multicolumn{2}{|l|}{ Baseline } & \multicolumn{2}{|l|}{ Intervention } & \multirow[t]{3}{*}{$p^{1}$} & \multirow[t]{3}{*}{$p^{2} \mathrm{TT}$} & \multirow[t]{3}{*}{$p^{2} \mathrm{CC}$} & \multirow[t]{3}{*}{$p^{3}$} \\
\hline & TT $(n=26)$ & $\mathrm{CC}(n=33)$ & TT $(n=26)$ & $\mathrm{CC}(n=33)$ & & & & \\
\hline & Median (IQR) & Median (IQR) & Median (IQR) & Median (IQR) & & & & \\
\hline Energy, kcal & $2226(2013 ; 2596)$ & $2286(2011 ; 2532)$ & $2519(2220 ; 2816)$ & $2639(2319 ; 2840)$ & 0.601 & 0.003 & $1.79 \mathrm{E}-05$ & 0.976 \\
\hline Carbohydrates, g & $220.4(183.9 ; 252.7)$ & $228.1(211.3 ; 279.1)$ & $228.8(201.0 ; 269.0)$ & $246.9(208.9 ; 278.5)$ & 0.417 & 0.920 & 1.000 & 0.905 \\
\hline $\begin{array}{l}\text { Carbohydrates, } \\
\text { E\% }\end{array}$ & $42.1(37.6 ; 46.1)$ & $39.6(38.3 ; 46)$ & $37.0(31.6 ; 41.8)$ & $37.2(33.6 ; 41.0)$ & 0.826 & 0.001 & 4.61E-05 & 0.710 \\
\hline Protein, $g$ & $95.9(88.4 ; 108.5)$ & $102.7(87.0 ; 120.2)$ & $92.0(79.6 ; 106.3)$ & $99.2(82.1 ; 108.1)$ & 0.644 & 0.036 & 0.235 & 0.345 \\
\hline Protein, E\% & $17.4(16.1 ; 20.4)$ & $17.7(15.9 ; 18.8)$ & $14.5(13.1 ; 16.2)$ & $14.5(13.6 ; 16.5)$ & 0.710 & 8.94E-08 & $5.53 \mathrm{E}-07$ & 0.175 \\
\hline Fat, g & $86.3(71.4 ; 98.8)$ & $87.9(71.4 ; 104.1)$ & $121.7(102.7 ; 135.8)$ & $121.3(106.9 ; 133.2)$ & 0.826 & $7.45 \mathrm{E}-07$ & $3.26 \mathrm{E}-09$ & 0.720 \\
\hline Fat, E\% & $34.7(30.1 ; 38.8)$ & $35.0(29.9 ; 37.8)$ & $44(40.4 ; 45.7)$ & $42.2(39.8 ; 45.0)$ & 0.958 & $1.28 \mathrm{E}-06$ & $1.25 \mathrm{E}-07$ & 0.907 \\
\hline SFA, g & $29.6(24.8 ; 34.9)$ & $29.1(25.2 ; 37.7)$ & $34.2(26.9 ; 40.1)$ & $33.9(28.6 ; 40.7)$ & 0.922 & 0.031 & 0.140 & 0.655 \\
\hline SFA, E\% & $11.9(9.5 ; 14.5)$ & $12.0(10.4 ; 13.3)$ & $12.3(11 ; 13.8)$ & $12.1(10.0 ; 13.1)$ & 0.910 & 1.000 & 0.458 & 0.259 \\
\hline MUFA, g & $28.2(23.4 ; 34.7)$ & $31.5(25.1 ; 38.8)$ & $37.9(30.9 ; 41.6)$ & $37.3(33.9 ; 42.5)$ & 0.500 & $1.66 \mathrm{E}-04$ & $3.40 \mathrm{E}-05$ & 0.728 \\
\hline MUFA, E\% & $11.6(11 ; 12.7)$ & $12.5(10.6 ; 13.8)$ & $13.4(12.5 ; 14.3)$ & $13.6(11.8 ; 14.2)$ & 0.601 & 0.003 & 0.006 & 0.620 \\
\hline PUFA, g & $13.8(11.6 ; 19.6)$ & $16.1(11.6 ; 19.8)$ & $36.4(32.1 ; 42.3)$ & $37.0(34.5 ; 40.7)$ & 0.631 & $1.49 \mathrm{E}-07$ & $2.33 \mathrm{E}-10$ & 0.804 \\
\hline PUFA, E\% & $5.9(5.1 ; 6.6)$ & $5.8(5.0 ; 7.1)$ & $13.2(12.5 ; 14.7)$ & $12.7(11.6 ; 14.3)$ & 0.946 & $5.96 \mathrm{E}-08$ & $2.33 \mathrm{E}-10$ & 0.818 \\
\hline LA, g & $8.7(7.4 ; 12.3)$ & $8.8(6.9 ; 11.8)$ & $30.9(26.9 ; 36.9)$ & $30.1(28.1 ; 34.6)$ & 0.898 & $5.96 \mathrm{E}-08$ & $2.33 \mathrm{E}-10$ & 0.605 \\
\hline LA, E\% & $3.6(3 ; 4.4)$ & $3.4(2.9 ; 4.4)$ & $11.1(10.7 ; 12.7)$ & $10.5(9.4 ; 12.2)$ & 0.874 & $5.96 \mathrm{E}-08$ & $2.33 \mathrm{E}-10$ & 0.446 \\
\hline ALA, g & $2.3(1.8 ; 3.4)$ & $2.2(1.5 ; 3.1)$ & $2.7(1.9 ; 3.0)$ & $2.3(2.0 ; 3.1)$ & 0.699 & 0.901 & 0.537 & 0.872 \\
\hline $\mathrm{EPA}, \mathrm{mg}$ & $75.6(22.7 ; 153.2)$ & $114.6(24.3 ; 258.6)$ & $58.2(36.4 ; 167.3)$ & $139.3(81.4 ; 269.7)$ & 0.417 & 0.548 & 0.491 & 0.387 \\
\hline DHA, mg & $216.6(69.1 ; 412.4)$ & $326.1(83.8 ; 735.8)$ & $193.4(90.6 ; 427.4)$ & $358.2(219.3 ; 670.9)$ & 0.305 & 0.353 & 0.548 & 0.575 \\
\hline$n-6 / n-3$ & $3.0(2.5 ; 3.5)$ & $2.8(2.2 ; 3.2)$ & $8.6(8 ; 10.1)$ & $7.3(6.2 ; 9.6)$ & 0.183 & 2.98E-08 & $2.33 \mathrm{E}-10$ & 0.955 \\
\hline LA / ALA & $3.9(3.6 ; 4.6)$ & $4.1(3.5 ; 4.6)$ & $12.6(11 ; 16)$ & $13(10.7 ; 14.6)$ & 0.779 & $2.98 \mathrm{E}-08$ & $2.33 \mathrm{E}-10$ & 0.727 \\
\hline Vitamin E, mg & $10.6(9.7 ; 15.1)$ & $11.7(8.8 ; 14.7)$ & $32.8(28.9 ; 39.9)$ & $33.8(29.8 ; 37.2)$ & 0.722 & $5.96 \mathrm{E}-08$ & $2.33 \mathrm{E}-10$ & 0.512 \\
\hline
\end{tabular}

Data are presented as median and interquartile range (IQR)

$p^{1}$; Mann-Whitney's $U$ test for baseline differences between the TT and CC genotypes, $p^{2}$; paired Wilcoxon test for the changes within genotypes, $p^{3}$; linear mixed effect model for significance of the responses between TT and CC genotype to high-LA diet

SFA saturated fatty acid, MUFA monounsaturated fatty acid, PUFA polyunsaturated fatty acid, LA linoleic acid, ALA alpha-linolenic acid, EPA eicosapentaenoic acid, DHA docosahexaenoic acid

Non-targeted metabolite profiling analysis revealed metabolites affected by the diet and the genotype. When focusing on the differential features between the genotypes, there were at the baseline 369 features with VIP $>1.5$ and 54 features with FDR $p$ value $<0.05$. For the changes observed during the intervention within the TT genotype group, the corresponding numbers were 314 and 37 and for the CC genotype 468 and 303. Total of 149 features showed nominally significant genotype $\times$ diet interaction, referring to differential response to high-LA diet between the carriers of the FADS1 rs174550 genotypes, out of which none were statistically significant after FDR correction. Total of 58 metabolites were identified: 19,25 , and 14 for level 1,2, and 3 identifications, respectively. List of all identified metabolites with analytical data are listed in Online Resources 2-4.

\section{Results}

\section{Dietary intakes before and during the FADSDIET intervention}

There were no differences in dietary intakes between the carriers of the TT and CC genotypes at the baseline or during the intervention (Table 2). Total energy (kcal), total fat (E\%), MUFA (E\%) and PUFA (E\%), and LA (g) and vitamin $\mathrm{E}(\mathrm{mg})$ intakes increased during the intervention in response to the high-LA diet. However, positive energy balance led to no significant weight gain [16]. Absolute dietary intakes of other PUFAs (ALA, EPA, and DHA) remained unchanged. 
Fig. 1 Scaled abundances of identified metabolites $(p<0.05$ or VIP $>1.5)$ at the baseline according to $F A D S 1$ rs 174550 genotypes $(\mathrm{TT}=$ yellow,

$\mathrm{CC}=$ blue). Size of the circle indicates $-\log 10$ transformed $p$ value of the Mann-Whitney U test; color of the circles indicates the value of VIP from the PLS-DA model. Black asterisks $(* *)$ indicate significant (FDR $p<0.05)$ and $(*)$ nominally significant $(p<0.05)$ difference at the baseline metabolite abundance between FADS1 genotypes

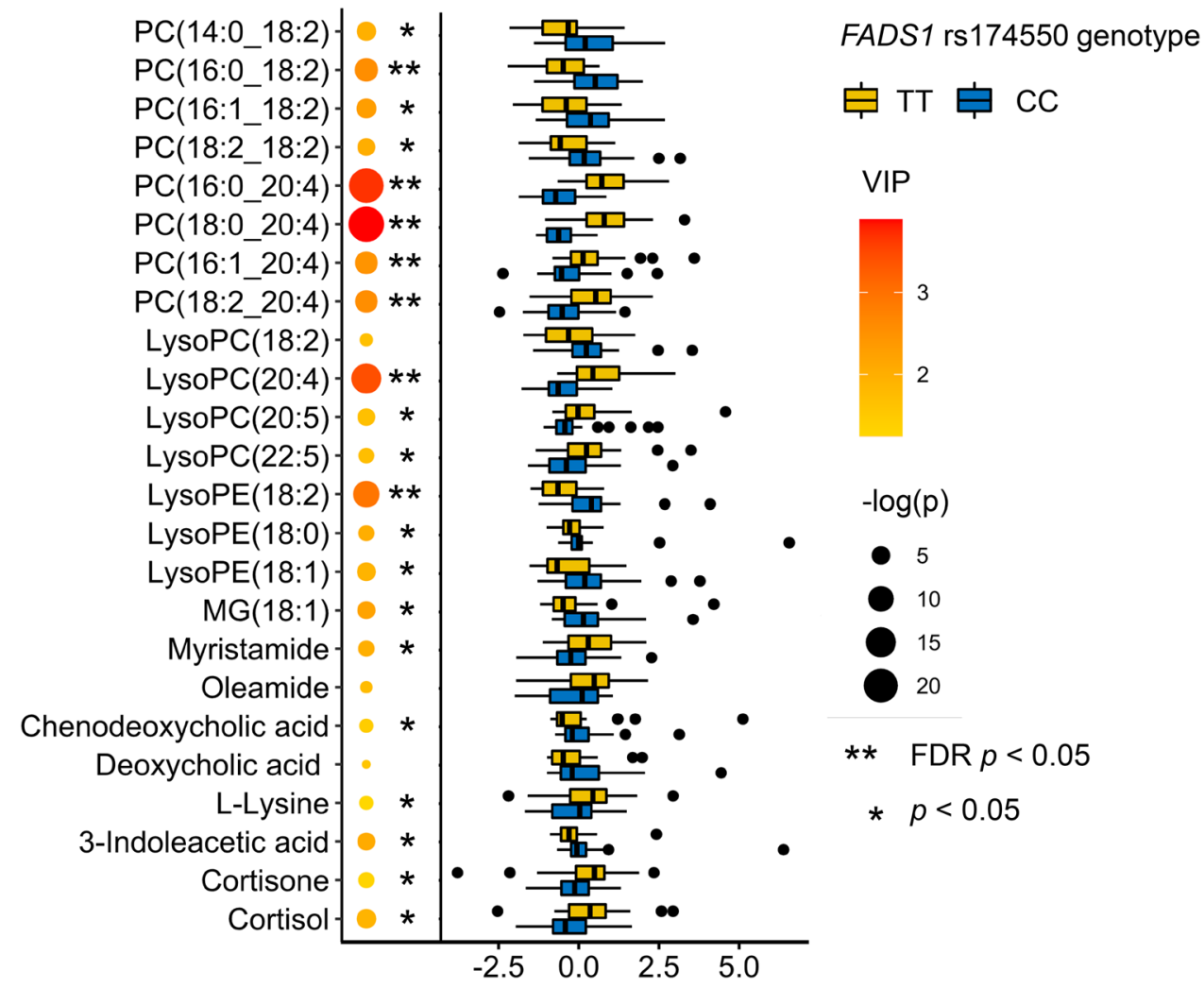

\section{Differences in the metabolic profiles at baseline between the carriers of FADS1 rs174550 genotypes}

The carriers of the FADS1 rs174550-TT genotype had higher abundances of long-chain PUFA phospholipids at the baseline. Abundances of phosphatidylcholines (PCs) PC(16:0_20:4), PC(18:0_20:4), PC(16:1_20:4), PC(18:2_20:4), and lysophosphatidylcholine (LysoPC) LysoPC (20:4) were significantly (FDR $p<0.05)$ higher in the carriers of the FADS1 rs174550-TT genotype (Fig. 1). The carriers of the rs 174550-CC genotype had significantly higher abundances of PC(16:0_18:2) and lysophosphatidylethanolamine (LysoPE) LysoPE(18:2). In addition to univariate statistics, differences between genotypes on plasma metabolite composition were analyzed with multivariate PLS-DA model. The carriers of the TT genotype, due to higher D5D activity, had higher (VIP $>1.5$ and $\left.p_{\text {unadjusted }}<0.05\right)$ abundances of phospholipids with LCPUFA including LysoPC (20:5) and LysoPC (22:5). The carriers of the CC genotype, with lower D5D activity, had also higher abundances of phospholipids with LA including PC(14:0_18:2), PC(16:1_18:2), and PC(18:2_18:2) (VIP $>1.5$ and $p_{\text {unadjusted }}<0.05$ ). Apart from fatty acids, the carriers of the TT genotype had higher abundances of amides (oleamide, myristamide) (VIP $>1.5$ ) and steroid hormones cortisol and cortisone (VIP $>1.5$ and $p_{\text {unadjusted }}<0.05$ ). Identified metabolites which differed between the metabolic profiles of FADS1 rs174550 TT and CC genotypes at baseline are shown in Fig. 1 and listed in Online Resources 3 and 4.

\section{Metabolic responses in plasma lipids induced by the high-LA diet}

The 4-week high-LA diet induced changes in fatty acid metabolites in both genotypes (Fig. 2A). Abundance of LysoPE(18:2) increased significantly in both genotypes in response to the high-LA diet. Fasting plasma abundances of long-chain acylcarnitines (LCACs) C18:2, C14:2, and C10:1 increased significantly in both genotypes (Fig. 2B). There was a tendency toward increased plasma abundance of other LA phospholipids and linoleamide and alpha-tocopherol in both genotypes. Plasma abundances of PC(16:1_20:4), LysoPC(20:5), LysoPC(22:6), and LysoPE(20:5) decreased significantly in both genotypes. LysoPC(18:0) increased, but significantly only in the carriers of the CC genotype.

After FDR correction, there were no statistically significant genotype $\mathrm{x}$ diet interactions. In spite of similar responses seen in LA phospholipids in both genotypes, there were genotype $\mathrm{x}$ diet interactions $\left(p_{\text {unadjusted }}<0.05\right)$ in AA phospholipids (Fig. 2A). This finding suggests that response to high-LA diet differs between the carriers of the FADS1 rs $174550 \mathrm{TT}$ and CC genotypes. Decrease in the plasma abundances of PC(16:0/20:4), 


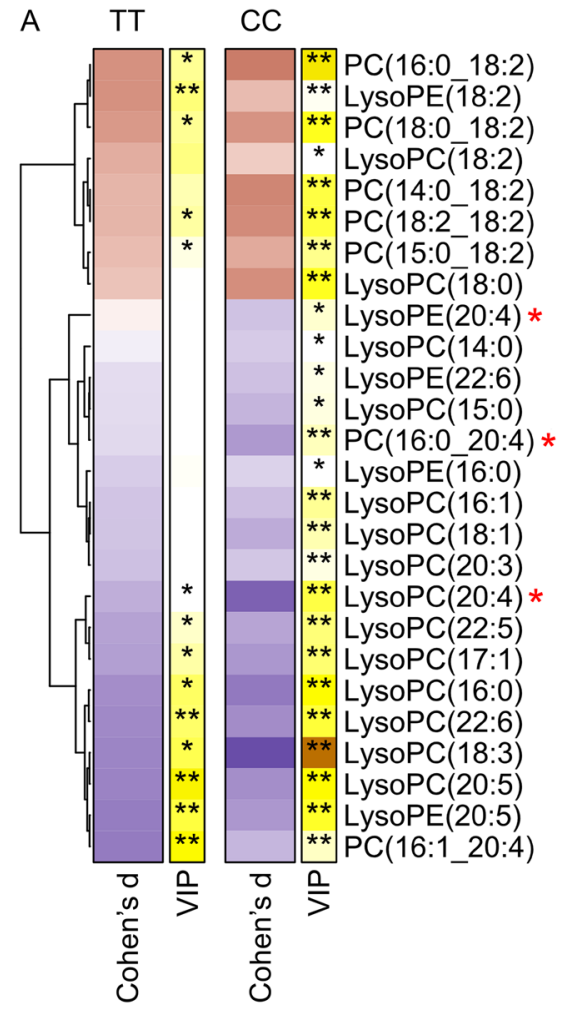

Fig. 2 Heatmaps showing changes induced by the dietary intervention in metabolic profiles of the FADS1 rs174550 CC and TT genotypes on $\mathbf{A}$ phospholipids and $\mathbf{B}$ other identified metabolites. Color of the cell indicates changes between baseline and week 4; red color for positive Cohen's d value (increased metabolite) and blue for negative Cohen's $d$ (decreased metabolite). VIP values of multilevel PLS-

LysoPC(20:4), and LysoPE(20:4) were strong for the CC genotype, whereas PC(16:0/20:4) and LysoPE(20:4) remained unchanged and $\operatorname{LysoPC}(20: 4)$ decreased only slightly for the TT genotype. From these, PC(16:0/20:4) and LysoPC(20:4) were higher in the TT genotype carriers at baseline.

We found a strong impact of FADS1 rs174550 genotype on the plasma abundances of AA and LA phospholipids. Overall patterns of changes in LA and AA phospholipids are illustrated in Fig. 2. During the high-LA diet, AA PCs consistently decreased or remained unchanged and LA PCs increased in both genotypes (Fig. 2). The difference on plasma abundances of these phospholipids, observed at baseline, was remained even at the end of the 4-week high-LA diet. Plasma abundances of LA phospholipids at week 4 in the TT genotype carriers were mainly lower than in the CC genotype carriers at baseline (Fig. 3).
DA models are shown with color scales and $p$ value of Wilcoxon test with asterisks, $* *=$ FDR $p<0.05$ and $*=p<0.05$. Red asterisk after metabolite name refers to genotype $\mathrm{x}$ diet interaction term $p$ value $<0.05$; after FDR correction, none of these were statistically significant

\section{Other metabolites associated with FADS1 rs 174550 genotype and the high-LA diet}

Cortisol and cortisone were nominally lower in the carriers of FADS1 rs174550-CC genotype compared to TT genotype carriers at baseline. There was a genotype $\mathrm{x}$ diet interaction ( $p_{\text {unadjusted }}=0.004$ ) for cortisol between the FADS1 rs174550 genotype carriers and a nominal increase in the $\mathrm{CC}$ genotype carriers in response to the high-LA diet (Fig. 2B). Plasma cortisol abundance remained unchanged in the TT genotype carriers during the study. There were also other significant changes during the study which occurred only in the carriers of the CC genotype. Hippuric acid significantly decreased in the carriers of the CC genotype, but remained unchanged in the carriers of the TT genotype (genotype $\times$ diet interaction $p_{\text {unadjusted }}=0.048$ ). Plasma abundances of guanosine and inosine nominally decreased and amino acids citrulline, L-Histidine, L-Methionine, and L-Phenylalanine nominally 
A PC(14:__18:2). $p=0.4$

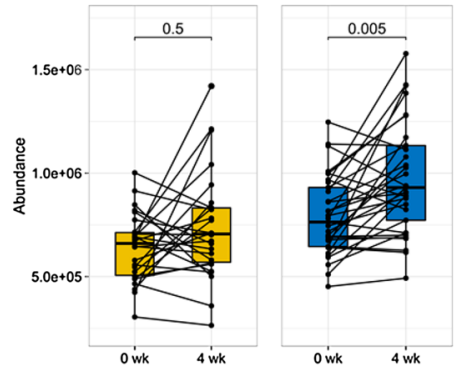

D $\quad P C\left(18: 0 \_18: 2\right), p=0.7$

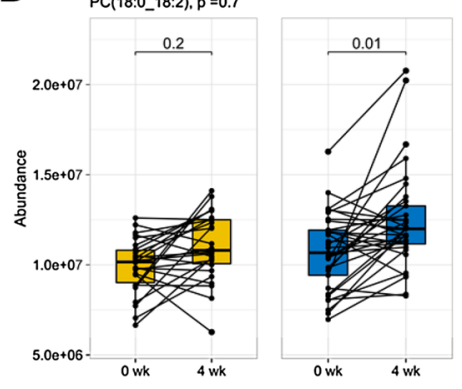

G $P C\left(16: 0 \_20: 4\right), p=0.001$

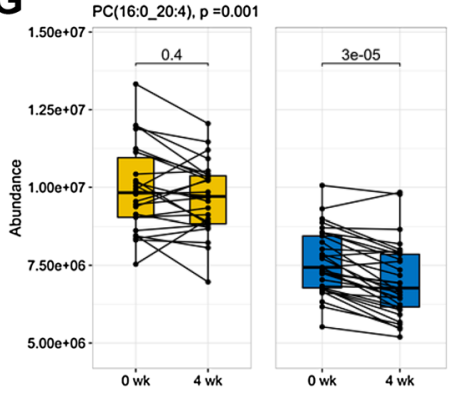

J

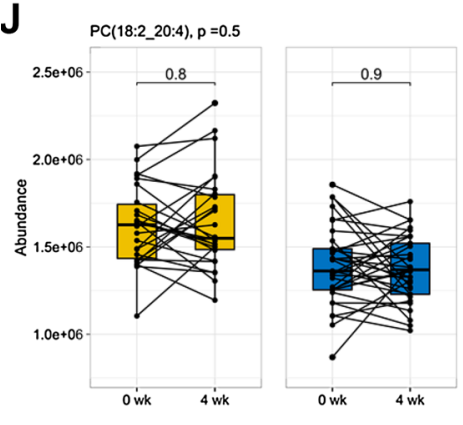

M

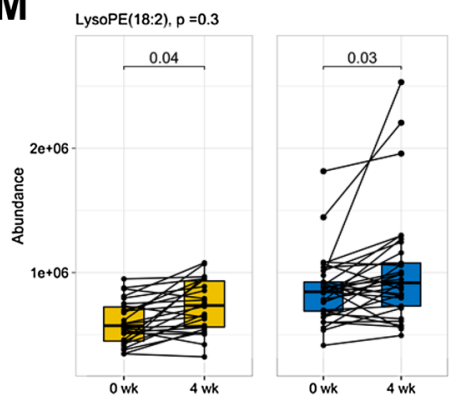

B $P C(150.1882 ., P=0.4$
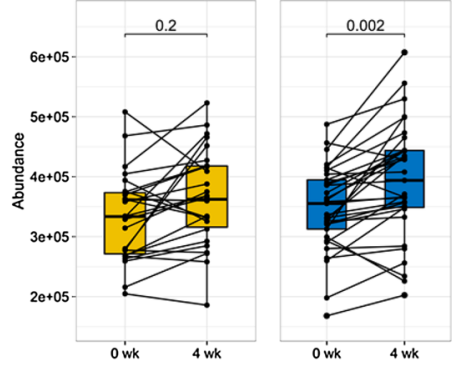

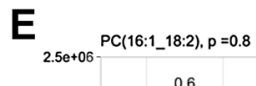
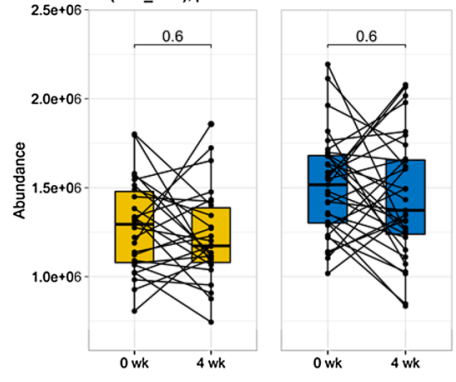

H $\quad \mathrm{PC}(18: 0200: 4), \mathrm{p}=0.4$
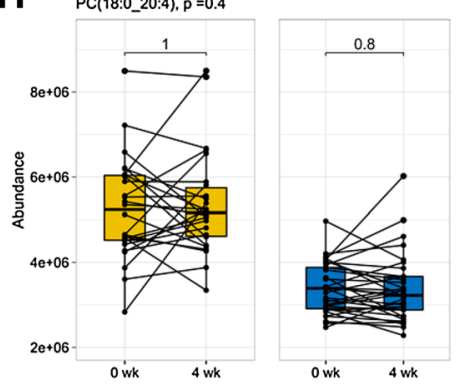

K

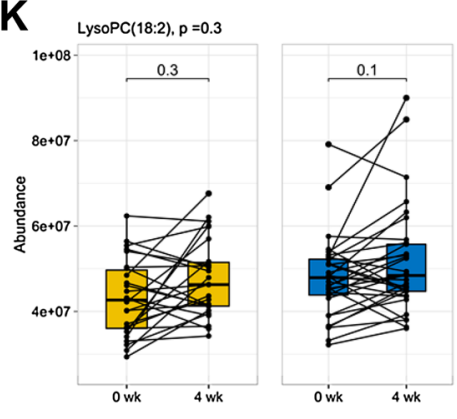

N

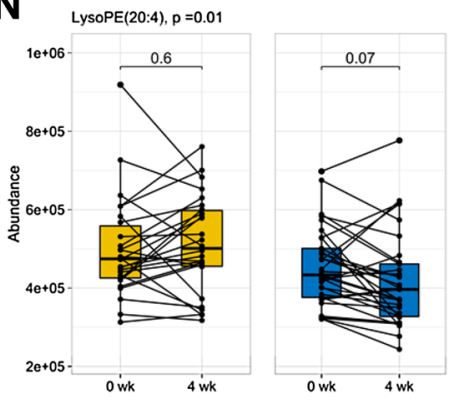

C $P C\left(16: 0 \_18: 2\right), p=0.3$

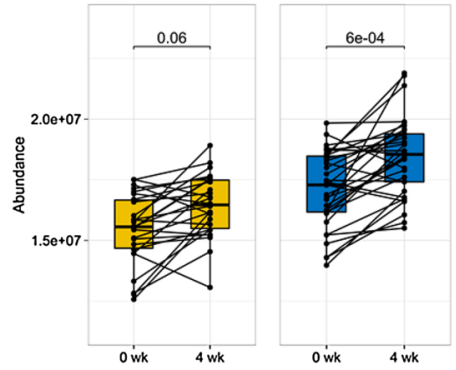

$\mathbf{F}$

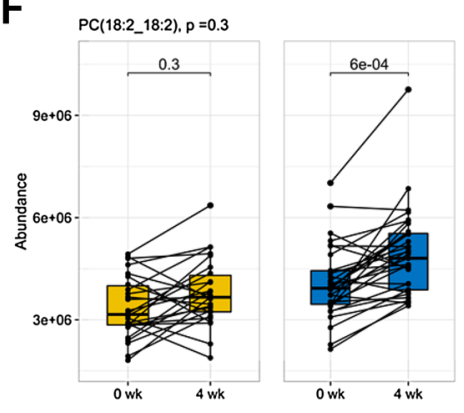

I

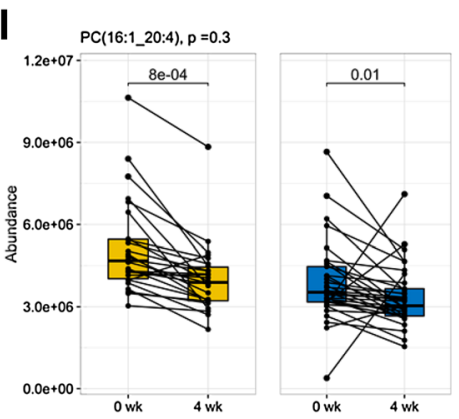

$\mathbf{L}$

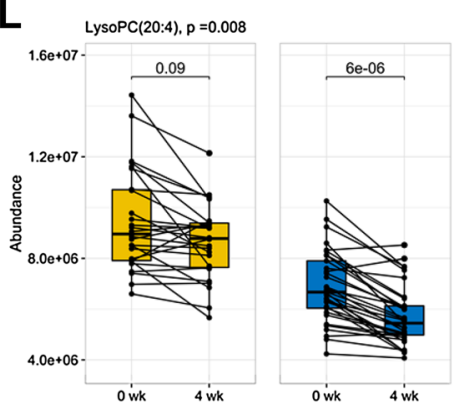

FADS1 rs174550 genotype

它 TT 白 CC 
4 Fig. 3 Boxplots of identified LA and AA phospholipids before and at the end of the 4-week high-LA diet according to FADS1 rs174550 genotypes. $P$ value in headline shows the genotype $\times$ diet interaction $p$ value; after FDR correction, none of these were statistically significant. $P$ value indicating within the genotype difference $(0$ week vs. 4 week) is FDR-corrected Wilcoxon test $p$ value. A PC(14:0_18:2), B PC(15:0_18:2), C PC(16:0_18:2), D PC(18:0_18:2), E $\mathrm{PC}\left(16: 1 \_18: \overline{2}\right), \quad \mathbf{F} \quad \mathrm{PC}\left(18: 2 \_18: 2\right), \quad \mathbf{G} \quad \mathrm{PC}\left(16: 0 \_20: 4\right), \quad \mathbf{H}$ PC(18:0_20:4), I PC(16:1_20:4), J PC(18:2_20:4), K LysoPC(18:2), L LysoPC(20:4), M LysoPE (18:2), and N LysoPE(20:4)

increased in the CC genotype carriers (Fig. 2B), but there were no genotype $\times$ diet interactions.

\section{Discussion}

Our study shows that metabolite profiles in healthy middle-aged Finnish men differ between the carriers of FADSI rs 174550-TT and -CC genotypes. Based on the 4-day food records at baseline, no differences existed in the dietary intakes of fatty acids. Despite of this, higher abundances of PC, LysoPC, and LysoPE species with an LC-PUFA, mainly AA, were found in the carriers of the rs174550TT genotype. This finding agrees with higher activity of D5D and more efficient conversion of LA to AA in carriers of the rs174550-TT genotype. In contrast, carriers of the rs174550-CC genotype had higher abundances of LA-rich phospholipids, probably due to lower D5D enzyme activity. The differences in the absolute abundances of LA and AA phospholipids in plasma observed at baseline between the carriers of the rs 174550 genotypes remained throughout the 4-week high-LA diet.

During the 4-week intervention, subjects consumed their habitual diets with sunflower oil supplementation to gain a high dose of LA. Daily supplementation increased median dietary intake of LA from $\sim 9 \mathrm{~g}$ to $\sim 30 \mathrm{~g}(\sim 3.5 \mathrm{E} \%$ to $\sim 11 \mathrm{E}$ $\%)$ in both groups. The relative energy intake from PUFA increased from $\sim 6$ to $\sim 13 \mathrm{E} \%$ and that of monounsaturated fatty acids (MUFA) from $\sim 12$ to $\sim 13 \mathrm{E} \%$. Although the diet was planned to be isocaloric, energy intake increased $~ 10 \%$ in both genotypes during the study. A careful documentation of the ingested sunflower oil may explain higher reported energy intake during the intervention, because no change in body weight was observed [16]. In response to the highLA diet, in both genotype carriers, LA-rich phospholipids and LCACs (C10:1, C14:2, C18:2) increased. Fasting plasma LCAC profiles resemble the fatty acid composition of the diet [27] and in response to dietary LA LCAC(18:2) increased. The increased plasma LCAC may be a marker of disrupted lipid flux through cell and mitochondria membranes and of incomplete $\beta$-oxidation of PUFAs due to excess fatty acid input into mitochondria as it was found in women with type 2 diabetes [28]. Both LCAC C14:2 and
C10:1 are chain-shortened derivates of the $\beta$-oxidation of $C 18: 2$. Higher $C(10: 1)$ may indicate reduced $\beta$-oxidation [29]. These changes in LCAC indicate changes in the energy metabolism in response to a high-LA diet in the carriers of FADS1 rs174550-TT and -CC genotypes.

Plasma abundances of identified AA phospholipids did not significantly increase due to the 4-week high-LA diet. One possible explanation for this is that the enzymes needed for the metabolism of LA were already saturated with the substrate LA. Thus, the high-LA diet caused no significant increase in AA in plasma phospholipids in subjects consuming diets with relatively high baseline LA intakes, regardless of their FADS1 rs 174550 genotype. It has been shown that abundance of LA inhibits D6D activity in fetal human liver [30]. This finding is in agreement with a previous study (all male participants), where there were no differences in the plasma concentrations or proportions of AA between high or low LA intakes with ratios of ALA to LA 1:4 and 1:10, respectively [31]. However, a recent study [32] showed that proportions of serum AA increase modestly, regardless of the FADS1 rs174537 genotype, in response to botanical oil rich in GLA, an n-6 PUFA, but not in response to an oil rich in LA. With a GLA enriched diet, the initial step of PUFA metabolism, conversion of LA to GLA by D6D, is bypassed.

In addition to the differences in lipid metabolites, several other classes of metabolites were affected by the genotype and dietary intervention. For example, before the intervention, carriers of the CC genotype had a nominally lower plasma abundance of cortisol and cortisone. During the intervention, cortisol nominally increased in the carriers of the CC genotype, but remained unchanged in the carriers of the TT genotype. This result supports the previous findings that the FADS1 rs174550 genotype modifies inflammatory response, measured as hs-CRP, to dietary LA [16]. The hs-CRP concentration decreased and increased in the carriers of the TT and CC genotype, respectively. Both increasing plasma LA and n-6:n-3 ratio in response to diet are shown to increase salivary cortisol excretion in vivo [33]. The mechanism how dietary LA and the FADS1 genotypes jointly modulate inflammatory responses remains unknown. In addition, the genotype-specific impact of the intervention on hippuric acid was an interesting observation warranting further focus on the role of genotype $\mathrm{x}$ diet interaction in gut microbiota function.

A recent study [12] showed that the FADS1 rs 174548 , which is in strong linkage disequilibrium with rs 174550 in the Finnish population [34], affects FADS1 and FADS2 gene expression in opposite directions in adipose tissue and skeletal muscle but not in liver. However, gene expression of FADS1 is higher in liver compared to adipose tissue [35]. Various tissues metabolize fatty acids [36], and plasma represents the mixture of all body metabolism. These facts about whole-body fatty acid metabolism and the effects 
of the FADS1 genotype on different tissues could in part explain our current results. The 4 -week time might be too short for incorporation and achieving metabolic balance of fatty acids in adipose tissue and other metabolically active tissues [37]. Tissue specific effects of the FADS1 variants together with dietary modification need to be studied to better understand mechanism behind observed changes and differences between the FADS1 genotypes.

We observed only large differences between the carriers of the FADS1 genotypes due to a relatively small sample size. A larger sample size would be needed to reliably observe also smaller changes in the metabolite profiles related to the FADS1 genotype. However, we observed the genotype-specific metabolic patterns at the baseline and responses to a high-LA diet in these metabolites. Some of the changes which were seen in the CC genotype carriers $(n=33)$, but not significantly in the TT genotype carriers $(n=26)$, might arise from the lack of statistical power. The genotype-based recruitment of male participants allowed to analyze the effects of the genetic variant with high effect size on fatty acids [16]. Collected food records allowed monitoring of the diet before and during the intervention. Compliance to daily sunflower oil supplementation was good, which together with non-targeted metabolomics approach allowed comprehensive analyses of the metabolic responses to a high-LA diet on human subjects.

In conclusion, we found that the carriers of the FADS1 rs 174550-TT genotype having higher D5D activity had higher abundances of AA phospholipids. Similarly, the lower D5D activity was observed as higher abundances of LA phospholipids in the carriers of the CC genotype. The high-LA diet increased abundances of LA phospholipids. Even though an increase in LA-rich phospholipids was similar in both genotypes during the intervention, our results show that the difference in the abundances of LA- and AArich phospholipids between the $F A D S 1$ rs174550 genotypes found at baseline remained at the end of the 4-week high-LA diet, and no gene-diet interaction was found.

Supplementary Information The online version contains supplementary material available at https://doi.org/10.1007/s00394-021-02722-w.

Acknowledgements We thank Taisa Venäläinen for the dietary counseling; Päivi Turunen, Tuomas Onnukka, and Matti Laitinen for assistance during the FADSDIET1 intervention; Marietta Kokla and Anton Klåvus for assistance with missing value imputation and statistical analyses; and personnel of Afekta Technologies for non-targeted metabolomics analyses.

Author contributions Research design: MAL, US, JP, and ML. Research execution: MAL, US, OK, and KH. Data interpretation and analysis: TM, OK, KH, US, and MAL. Manuscript preparation: TM, US, MAL, KH, JP, ML, and OK.
Funding Open access funding provided by University of Eastern Finland (UEF) including Kuopio University Hospital. Supported by the Finnish Cultural Foundation, the Northern Savo Regional Fund (MAL), the Academy of Finland (MAL 309311, KH 334814, 321716), the University of Eastern Finland Spearhead Funding (JP), and the Juho Vainio Foundation (US). Bunge Finland Ltd. provided oils.

Availability of data and materials Data described in the manuscript will not be made available, because ethical approval forbids research data sharing.

\section{Declarations}

Conflict of interest Olli Kärkkäinen and Kati Hanhineva are founders of Afekta Technologies Ltd., a company providing metabolomics analysis services. Other authors declare that they have no known competing financial interests or personal relationships that could have appeared to influence the work reported in this paper.

Ethics approval The study plan was approved by the Ethical Committee of the Hospital District of Northern Savo (75//2014).

Consent to participate Written informed consent was obtained from all participants.

Consent for publication All authors reviewed and approved the final version of the manuscript.

Open Access This article is licensed under a Creative Commons Attribution 4.0 International License, which permits use, sharing, adaptation, distribution and reproduction in any medium or format, as long as you give appropriate credit to the original author(s) and the source, provide a link to the Creative Commons licence, and indicate if changes were made. The images or other third party material in this article are included in the article's Creative Commons licence, unless indicated otherwise in a credit line to the material. If material is not included in the article's Creative Commons licence and your intended use is not permitted by statutory regulation or exceeds the permitted use, you will need to obtain permission directly from the copyright holder. To view a copy of this licence, visit http://creativecommons.org/licenses/by/4.0/.

\section{References}

1. Wu JHY, Marklund M, Imamura F, Tintle N, Ardisson Korat AV, de Goede J, Zhou X, Yang WS, de Oliveira Otto MC, Kröger J, Qureshi W, Virtanen JK, Bassett JK, Frazier-Wood AC, Lankinen M, Murphy RA, Rajaobelina K, Del Gobbo LC, Forouhi NG, Luben R, Khaw KT, Wareham N, Kalsbeek A, Veenstra J, Luo J, Hu FB, Lin HJ, Siscovick DS, Boeing H, Chen TA, Steffen B, Steffen LM, Hodge A, Eriksdottir G, Smith AV, Gudnason V, Harris TB, Brouwer IA, Berr C, Helmer C, Samieri C, Laakso M, Tsai MY, Giles GG, Nurmi T, Wagenknecht L, Schulze MB, Lemaitre RN, Chien KL, Soedamah-Muthu SS, Geleijnse JM, Sun Q, Harris WS, Lind L, Ärnlöv J, Riserus U, Micha R, Mozaffarian D (2017) Omega-6 fatty acid biomarkers and incident type 2 diabetes: pooled analysis of individual-level data for 39740 adults from 20 prospective cohort studies. Lancet Diabetes Endocrinol 5:965-974. https://doi.org/10.1016/s2213-8587(17)30307-8

2. Marklund M, Wu JHY, Imamura F, Del Gobbo LC, Fretts A, de Goede J, Shi P, Tintle N, Wennberg M, Aslibekyan S, Chen TA, de Oliveira Otto MC, Hirakawa Y, Eriksen HH, Kröger J, 
Laguzzi F, Lankinen M, Murphy RA, Prem K, Samieri C, Virtanen J, Wood AC, Wong K, Yang WS, Zhou X, Baylin A, Boer JMA, Brouwer IA, Campos H, Chaves PHM, Chien KL, de Faire U, Djoussé L, Eiriksdottir G, El-Abbadi N, Forouhi NG, Michael Gaziano J, Geleijnse JM, Gigante B, Giles G, Guallar E, Gudnason V, Harris T, Harris WS, Helmer C, Hellenius ML, Hodge A, Hu FB, Jacques PF, Jansson JH, Kalsbeek A, Khaw KT, Koh WP, Laakso M, Leander K, Lin HJ, Lind L, Luben R, Luo J, McKnight B, Mursu J, Ninomiya T, Overvad K, Psaty BM, Rimm E, Schulze MB, Siscovick D, Skjelbo Nielsen M, Smith AV, Steffen BT, Steffen L, Sun Q, Sundström J, Tsai MY, Tunstall-Pedoe H, Uusitupa MIJ, van Dam RM, Veenstra J, Monique Verschuren WM, Wareham N, Willett W, Woodward M, Yuan JM, Micha R, Lemaitre RN, Mozaffarian D, Risérus U (2019) Biomarkers of dietary omega- 6 fatty acids and incident cardiovascular disease and mortality. Circulation 139:2422-2436. https://doi.org/10. 1161/circulationaha.118.038908

3. Qian F, Ardisson Korat AV, Imamura F, Marklund M, Tintle N, Virtanen JK, Zhou X, Bassett JK, Lai H, Hirakawa Y, Chien KL, Wood AC, Lankinen M, Murphy RA, Samieri C, Pertiwi K, de Mello VD, Guan W, Forouhi NG, Wareham N, Hu I, Riserus U, Lind L, Harris WS, Shadyab AH, Robinson JG, Steffen LM, Hodge A, Giles GG, Ninomiya T, Uusitupa M, Tuomilehto J, Lindström J, Laakso M, Siscovick DS, Helmer C, Geleijnse JM, Wu JHY, Fretts A, Lemaitre RN, Micha R, Mozaffarian D, Sun Q (2021) n-3 fatty acid biomarkers and incident type 2 diabetes: an individual participant-level pooling project of 20 prospective cohort studies. Diabetes Care. https://doi.org/10.2337/dc20-2426

4. Lankinen M, Uusitupa M, Schwab U (2018) Genes and dietary fatty acids in regulation of fatty acid composition of plasma and erythrocyte membranes. Nutrients. https://doi.org/10.3390/nu101 11785

5. Saini RK, Keum Y-S (2018) Omega-3 and omega-6 polyunsaturated fatty acids: dietary sources, metabolism, and significanceA review. Life Sci 203:255-267. https://doi.org/10.1016/j.lfs. 2018.04.049

6. Glaser C, Heinrich J, Koletzko B (2010) Role of FADS1 and FADS2 polymorphisms in polyunsaturated fatty acid metabolism. Metabolism 59:993-999. https://doi.org/10.1016/j.metabol.2009. 10.022

7. Merino DM, Johnston H, Clarke S, Roke K, Nielsen D, Badawi A, El-Sohemy A, Ma DW, Mutch DM (2011) Polymorphisms in FADS1 and FADS2 alter desaturase activity in young Caucasian and Asian adults. Mol Genet Metab 103:171-178. https://doi.org/ 10.1016/j.ymgme.2011.02.012

8. Abdelmagid SA, Clarke SE, Roke K, Nielsen DE, Badawi A, ElSohemy A, Mutch DM, Ma DWL (2015) Ethnicity, sex, FADS genetic variation, and hormonal contraceptive use influence delta-5- and delta-6-desaturase indices and plasma docosahexaenoic acid concentration in young Canadian adults: a cross-sectional study. Nutr Metab (Lond) 12:14. https://doi.org/10.1186/ s12986-015-0010-9

9. Mathias RA, Sergeant S, Ruczinski I, Torgerson DG, Hugenschmidt CE, Kubala M, Vaidya D, Suktitipat B, Ziegler JT, Ivester P, Case D, Yanek LR, Freedman BI, Rudock ME, Barnes KC, Langefeld CD, Becker LC, Bowden DW, Becker DM, Chilton FH (2011) The impact of FADS genetic variants on $\omega 6$ polyunsaturated fatty acid metabolism in African Americans. BMC Genet 12:50. https://doi.org/10.1186/1471-2156-12-50

10. Ameur A, Enroth S, Johansson A, Zaboli G, Igl W, Johansson ACV, Rivas MA, Daly MJ, Schmitz G, Hicks AA, Meitinger T, Feuk L, van Duijn C, Oostra B, Pramstaller PP, Rudan I, Wright AF, Wilson JF, Campbell H, Gyllensten U (2012) Genetic adaptation of fatty-acid metabolism: a human-specific haplotype increasing the biosynthesis of long-chain omega- 3 and omega- 6 fatty acids. Am J Hum Genet 90:809-820. https://doi.org/10.1016/j. ajhg.2012.03.014

11. Blasbalg TL, Hibbeln JR, Ramsden CE, Majchrzak SF, Rawlings RR (2011) Changes in consumption of omega- 3 and omega- 6 fatty acids in the United States during the 20th century. Am J Clin Nutr 93:950-962. https://doi.org/10.3945/ajcn.110.006643

12. Reynolds LM, Howard TD, Ruczinski I, Kanchan K, Seeds MC, Mathias RA, Chilton FH (2018) Tissue-specific impact of FADS cluster variants on FADS1 and FADS2 gene expression. PLoS One 13:e0194610. https://doi.org/10.1371/journal.pone. 0194610

13. He Z, Zhang R, Jiang F, Zhang H, Zhao A, Xu B, Jin L, Wang T, Jia W, Jia W, Hu C (2018) FADS1-FADS2 genetic polymorphisms are associated with fatty acid metabolism through changes in DNA methylation and gene expression. Clin Epigenetics 10:113. https://doi.org/10.1186/s13148-018-0545-5

14. Klingel SL, Valsesia A, Astrup A, Kunesova M, Saris WHM, Langin D, Viguerie N, Mutch DM (2019) FADS1 genotype is distinguished by human subcutaneous adipose tissue fatty acids, but not inflammatory gene expression. Int J Obes 43:1539-1548. https://doi.org/10.1038/s41366-018-0169-z

15. Kathiresan S, Willer CJ, Peloso GM, Demissie S, Musunuru K, Schadt EE, Kaplan L, Bennett D, Li Y, Tanaka T, Voight BF, Bonnycastle LL, Jackson AU, Crawford G, Surti A, Guiducci C, Burtt NP, Parish S, Clarke R, Zelenika D, Kubalanza KA, Morken MA, Scott LJ, Stringham HM, Galan P, Swift AJ, Kuusisto J, Bergman RN, Sundvall J, Laakso M, Ferrucci L, Scheet P, Sanna S, Uda M, Yang Q, Lunetta KL, Dupuis J, de Bakker PIW, O’Donnell CJ, Chambers JC, Kooner JS, Hercberg S, Meneton P, Lakatta EG, Scuteri A, Schlessinger D, Tuomilehto J, Collins FS, Groop L, Altshuler D, Collins R, Lathrop GM, Melander O, Salomaa V, Peltonen L, Orho-Melander M, Ordovas JM, Boehnke M, Abecasis GR, Mohlke KL, Cupples LA (2009) Common variants at 30 loci contribute to polygenic dyslipidemia. Nat Genet 41:56-65. https://doi.org/10.1038/ng.291

16. Lankinen MA, Fauland A, Shimizu B-i, Ågren J, Wheelock CE, Laakso M, Schwab U, Pihlajamäki J (2019) Inflammatory response to dietary linoleic acid depends on FADS1 genotype. Am J Clin Nutr 109:165-175. https://doi.org/10.1093/ajcn/nqy287

17. Stančáková A, Paananen J, Soininen P, Kangas AJ, Bonnycastle LL, Morken MA, Collins FS, Jackson AU, Boehnke ML, Kuusisto J, Ala-Korpela M, Laakso M (2011) Effects of 34 risk loci for type 2 diabetes or hyperglycemia on lipoprotein subclasses and their composition in 6,580 nondiabetic finnish men. Diabetes 60:1608-1616. https://doi.org/10.2337/db10-1655

18. Dupuis J, Langenberg C, Prokopenko I, Saxena R, Soranzo N, Jackson AU, Wheeler E, Glazer NL, Bouatia-Naji N, Gloyn AL, Lindgren CM, Mägi R, Morris AP, Randall J, Johnson T, Elliott P, Rybin D, Thorleifsson G, Steinthorsdottir V, Henneman P, Grallert H, Dehghan A, Hottenga JJ, Franklin CS, Navarro P, Song K, Goel A, Perry JRB, Egan JM, Lajunen T, Grarup N, Spars $\varnothing$ T, Doney A, Voight BF, Stringham HM, Li M, Kanoni S, Shrader P, Cavalcanti-Proença C, Kumari M, Qi L, Timpson NJ, Gieger C, Zabena C, Rocheleau G, Ingelsson E, An P, O’Connell J, Ja L, Elliott A, McCarroll SA, Payne F, Roccasecca RM, Pattou F, Sethupathy P, Ardlie K, Ariyurek Y, Balkau B, Barter P, Beilby JP, BenShlomo Y, Benediktsson R, Bennett AJ, Bergmann S, Bochud M, Boerwinkle E, Bonnefond A, Bonnycastle LL, Borch-Johnsen K, Böttcher Y, Brunner E, Bumpstead SJ, Charpentier G, Chen Y-DI, Chines P, Clarke R, Coin LJM, Cooper MN, Cornelis M, Crawford G, Crisponi L, Day INM, de Geus EJC, Delplanque J, Dina C, Erdos MR, Fedson AC, Fischer-Rosinsky A, Forouhi NG, Fox CS, Frants R, Franzosi MG, Galan P, Goodarzi MO, Graessler J, Groves CJ, Grundy S, Gwilliam R, Gyllensten U, Hadjadj S, Hallmans G, Hammond N, Han X, Hartikainen A-L, Hassanali N, Hayward C, Heath SC, Hercberg S, Herder C, Hicks AA, Hillman 
DR, Hingorani AD, Hofman A, Hui J, Hung J, Isomaa B, Johnson PRV, Jørgensen T, Jula A, Kaakinen M, Kaprio J, Kesaniemi YA, Kivimaki M, Knight B, Koskinen S, Kovacs P, Kyvik KO, Lathrop GM, Lawlor DA, Le Bacquer O, Lecoeur C, Li Y, Lyssenko V, Mahley R, Mangino M, Manning AK, Martínez-Larrad MT, McAteer JB, McCulloch LJ, McPherson R, Meisinger C, Melzer D, Meyre D, Mitchell BD, Morken MA, Mukherjee S, Naitza S, Narisu N, Neville MJ, Oostra BA, Orrù M, Pakyz R, Palmer CNA, Paolisso G, Pattaro C, Pearson D, Peden JF, Pedersen NL, Perola M, Pfeiffer AFH, Pichler I, Polasek O, Posthuma D, Potter SC, Pouta A, Province MA, Psaty BM, Rathmann W, Rayner NW, Rice K, Ripatti S, Rivadeneira F, Roden M, Rolandsson O, Sandbaek A, Sandhu M, Sanna S, Sayer AA, Scheet P, Scott LJ, Seedorf U, Sharp SJ, Shields B, Sigurðsson G, Sijbrands EJG, Silveira A, Simpson L, Singleton A, Smith NL, Sovio U, Swift A, Syddall H, Syvänen A-C, Tanaka T, Thorand B, Tichet J, Tönjes A, Tuomi T, Uitterlinden AG, van Dijk KW, van Hoek M, Varma D, Visvikis-Siest S, Vitart V, Vogelzangs N, Waeber G, Wagner PJ, Walley A, Walters GB, Ward KL, Watkins H, Weedon MN, Wild SH, Willemsen G, Witteman JCM, Yarnell JWG, Zeggini E, Zelenika D, Zethelius B, Zhai G, Zhao JH, Zillikens MC, Borecki IB, Loos RJF, Meneton P, Magnusson PKE, Nathan DM, Williams GH, Hattersley AT, Silander K, Salomaa V, Smith GD, Bornstein SR, Schwarz P, Spranger J, Karpe F, Shuldiner AR, Cooper C, Dedoussis GV, Serrano-Ríos M, Morris AD, Lind L, Palmer LJ, Hu FB, Franks PW, Ebrahim S, Marmot M, Kao WHL, Pankow JS, Sampson MJ, Kuusisto J, Laakso M, Hansen T, Pedersen O, Pramstaller PP, Wichmann HE, Illig T, Rudan I, Wright AF, Stumvoll M, Campbell H, Wilson JF, Bergman RN, Buchanan TA, Collins FS, Mohlke KL, Tuomilehto J, Valle TT, Altshuler D, Rotter JI, Siscovick DS, Penninx BWJH, Boomsma DI, Deloukas P, Spector TD, Frayling TM, Ferrucci L, Kong A, Thorsteinsdottir U, Stefansson K, van Duijn CM, Aulchenko YS, Cao A, Scuteri A, Schlessinger D, Uda M, Ruokonen A, Jarvelin M-R, Waterworth DM, Vollenweider P, Peltonen L, Mooser V, Abecasis GR, Wareham NJ, Sladek R, Consortium D, Consortium G, Global BC, Anders Hamsten on behalf of Procardis C, the Mi (2010) New genetic loci implicated in fasting glucose homeostasis and their impact on type 2 diabetes risk. Nat Genet 42:105-116. https://doi.org/10.1038/ng.520

19. Kirwan JA, Broadhurst DI, Davidson RL, Viant MR (2013) Characterising and correcting batch variation in an automated direct infusion mass spectrometry (DIMS) metabolomics workflow. Anal Bioanal Chem 405:5147-5157. https://doi.org/10.1007/ s00216-013-6856-7

20. Stekhoven DJ, Bühlmann P (2011) MissForest-non-parametric missing value imputation for mixed-type data. Bioinformatics 28:112-118. https://doi.org/10.1093/bioinformatics/btr597

21. Lê Cao K-A, Boitard S, Besse P (2011) Sparse PLS discriminant analysis: biologically relevant feature selection and graphical displays for multiclass problems. BMC Bioinformatics 12:253. https://doi.org/10.1186/1471-2105-12-253

22. Durlak JA (2009) How to select, calculate, and interpret effect sizes. J Pediatr Psychol 34:917-928. https://doi.org/10.1093/ jpepsy/jsp004

23. Gu Z, Eils R, Schlesner M (2016) Complex heatmaps reveal patterns and correlations in multidimensional genomic data. Bioinformatics 32:2847-2849. https://doi.org/10.1093/bioinformatics/ btw313

24. Tsugawa H, Cajka T, Kind T, Ma Y, Higgins B, Ikeda K, Kanazawa M, VanderGheynst J, Fiehn O, Arita M (2015) MS-DIAL: data-independent MS/MS deconvolution for comprehensive metabolome analysis. Nat Methods 12:523-526. https://doi.org/ 10.1038/nmeth.3393
25. Wishart DS, Feunang YD, Marcu A, Guo AC, Liang K, VazquezFresno R, Sajed T, Johnson D, Li C, Karu N, Sayeeda Z, Lo E, Assempour N, Berjanskii M, Singhal S, Arndt D, Liang Y, Badran H, Grant J, Serra-Cayuela A, Liu Y, Mandal R, Neveu V, Pon A, Knox C, Wilson M, Manach C, Scalbert A (2018) HMDB 4.0: the human metabolome database for 2018. Nucleic Acids Res 46:D608-d617. https://doi.org/10.1093/nar/gkx1089

26. Smith CA, Maille GO, Want EJ, Qin C, Trauger SA, Brandon TR, Custodio DE, Abagyan R, Siuzdak G (2005) METLIN: a metabolite mass spectral database. Ther Drug Monit 27:747-751. https:// doi.org/10.1097/01.ftd.0000179845.53213.39

27. Kien CL, Everingham KI, Stevens RD, Fukagawa NK, Muoio DM (2011) Short-term effects of dietary fatty acids on muscle lipid composition and serum acylcarnitine profile in human subjects. Obesity (Silver Spring) 19:305-311. https://doi.org/10.1038/oby. 2010.135

28. Adams SH, Hoppel CL, Lok KH, Zhao L, Wong SW, Minkler PE, Hwang DH, Newman JW, Garvey WT (2009) Plasma acylcarnitine profiles suggest incomplete long-chain fatty acid $\beta$-oxidation and altered tricarboxylic acid cycle activity in type 2 diabetic African-American women. J Nutr 139:1073-1081. https://doi.org/10. 3945/jn.108.103754

29. Mihalik SJ, Michaliszyn SF, de las Heras J, Bacha F, Lee S, Chace DH, DeJesus VR, Vockley J, Arslanian SA (2012) Metabolomic profiling of fatty acid and amino acid metabolism in youth with obesity and type 2 diabetes: evidence for enhanced mitochondrial oxidation. Diabetes Care 35:605-611. https://doi.org/10.2337/ dc11-1577

30. Rodriguez A, Sarda P, Nessmann C, Boulot P, Leger CL, Descomps B (1998) Delta6- and delta5-desaturase activities in the human fetal liver: kinetic aspects. J Lipid Res 39:1825-1832

31. Angela Liou Y, Innis SM (2009) Dietary linoleic acid has no effect on arachidonic acid, but increases n-6 eicosadienoic acid, and lowers dihomo- $\gamma$-linolenic and eicosapentaenoic acid in plasma of adult men. Prostaglandins Leukot Essent Fatty Acids 80:201-206. https://doi.org/10.1016/j.plefa.2009.02.003

32. Sergeant S, Hallmark B, Mathias RA, Mustin TL, Ivester P, Bohannon ML, Ruczinski I, Johnstone L, Seeds MC, Chilton FH (2020) Prospective clinical trial examining the impact of genetic variation in FADS1 on the metabolism of linoleic acidand y-linolenic acid-containing botanical oils. Am J Clin Nutr 111:1068-1078. https://doi.org/10.1093/ajcn/nqaa023

33. Nemeth M, Millesi E, Wagner K-H, Wallner B (2018) Saliva cortisol responses to altered plasma PUFA patterns in guinea pigs. Br J Nutr 120:1240-1251. https://doi.org/10.1017/S000711451 8002660

34. Machiela MJ, Chanock SJ (2015) LDlink: a web-based application for exploring population-specific haplotype structure and linking correlated alleles of possible functional variants. Bioinformatics 31:3555-3557. https://doi.org/10.1093/bioinformatics/btv402

35. Vaittinen M, Männistö V, Käkelä P, Ågren J, Tiainen M, Schwab U, Pihlajamäki J (2017) Interorgan cross talk between fatty acid metabolism, tissue inflammation, and FADS2 genotype in humans with obesity. Obesity (Silver Spring) 25:545-552. https://doi.org/ 10.1002/oby. 21753

36. Frayn KN, Arner P, Yki-Järvinen H (2006) Fatty acid metabolism in adipose tissue, muscle and liver in health and disease. Essays Biochem 42:89-103. https://doi.org/10.1042/bse0420089

37. Hodson L, Skeaff CM, Fielding BA (2008) Fatty acid composition of adipose tissue and blood in humans and its use as a biomarker of dietary intake. Prog Lipid Res 47:348-380. https://doi.org/10. 1016/j.plipres.2008.03.003 